\title{
KOKIE FAKTORIAI KARDIOLOGINĖJE INTENSYVIOJE TERAPIJOJE TURI İTAKOS ŪMINIU MIOKARDO INFARKTU SIRGUSIŲ PACIENŲ DIDIESIEMS KRAUJAVIMAMS?
}

\author{
Pranas Šerpytis ${ }^{1,2}$, Audronė Beržiūnaitė ${ }^{2}$ Vilma Matelytė ${ }^{2}$ Živilè Lileikiené2 \\ Agnẻ Andruškiené ${ }^{1}$ \\ ${ }^{1}$ Vilniaus universiteto Medicinos fakultetas, ${ }^{2}$ Vilniaus universiteto ligoninès Santariškiu klinikos
}

Raktažodžiai: kraujavimas, miokardo infarktas, perkutanine koronarinè intervencija, mirtingumas.

\begin{abstract}
Santrauka
Darbo tikslas: išnagrinèti 2010 m.- 2012 m. Vilniaus universiteto ligoninès Santariškių klinikų Kardiologinès reanimacijos ir intensyvios terapijos skyriuje dèl üminio miokardo infarkto gydytų pacientų kraujavimų dažnị pagal amžių, lytį, lokalizaciją, šalutines ligas, skirtų vaistų derinius, mirtingumą ir kraujavusių pacientų mirčių pasiskirstymą pagal lytį. Medžiaga ir metodai: išanalizuoti 223 pacientų medicininių ịrašų duomenys. Šių pacientų amžiaus vidurkis $75 \pm 1,7 \mathrm{~m}$. Kraujavimas po perkutaninès koronarinès intervencijos konstatuotas 33\% pacientams, sirgusiems ūminiu miokardo infarktu. Atrankos kriterijai - kraujavusių pacientų lytis, amžius, kraujavimo lokalizacija, šalutinès ligos, paskirtu vaistų deriniai, mirtingumas.

Rezultatai: kraujavimu pasiskirstymas pagal lyti moteru 55\%, vyrų 45\% (p=0,034). Kraujavusiųjų hemoglobino koncentracija buvo mažesnè nei 90 $\mathrm{g} / 1(\mathrm{p}=0,001)$. Amžiaus grupèse daugiausia kraujavimų turèjo pacientai $>60 \mathrm{~m} .(87 \%)(\mathrm{p}=0,001)$. Gautas statistiškai patikimas didžiausias kraujavimų dažnis iš virškinimo trakto $(44 \%)$ ir a.femoralis $(30 \%)(\mathrm{p}=0,008)$. Nustatyta, kad $81 \%$ kraujavusiųų turejjo šalutines ligas: inkstų funkcijos nepakankamumą $11 \%$, prieširdžių virpejjimą $26 \%$, opaligę $19 \%$, cukrinį diabetą $15 \%$, onkologinę ligą $10 \%$ $(\mathrm{p}=0,025)$. Daugiausia kraujavimu i ivyko kartu skiriant hepariną, aspiriną ir klopidogreli $-34 \%(\mathrm{p}=$ 0,003). Kraujavusiu pacientu pasiskirstymas pagal mirtingumą: $16 \%$ turèjo letalią baigti $(\mathrm{p}=0,0076)$, iš kurių moterys sudare didesnę dalị nei vyrai, atitinkamai $-58 \%, 42 \%$.
\end{abstract}

Išvados: intensyvios terapijos skyriuje daugiausia kraujavimų buvo $>60 \mathrm{~m}$. amžiaus tiriamųų grupèje, turintiems šalutines ligas, moteriškos lyties atstovèms, virškinamo trakte ir iš a.femoralis, skiriant kartu hepariną, aspiriną ir klopidogrelį. Nustatyta, kad kraujavusių pacientų mirties atvejai dažnesni moterims. Esant šioms išvardintoms tiriamųų rizikos grupèms, turetų būti koreguojamas gydymas antikoaguliaciniais vaistais, dèl mažesnio komplikacijų dažnio rekomenduojamas kateterizavimas per a.radialis / brachialis.

\section{Ivadas}

Intervencinès kardiologijos istorijoje minimas Vokietijos kardiologas Andreas Gruentzig, kuris 1977 rugsejjo 16 d. atliko pirmą kateterizaciją Ciuriche. Nuo to laiko prasidejjo perkutaninès koronarinès intervencijos (PKI) era, sudariusi galimybę nechirurginiu, mažiau žalojančiu būdu - atliekant per šlaunies, žasto ar radialinę arterijas, atkurti koronarinę kraujotaką. Prièjimas per šlaunies arteriją buvo ir yra pagrindinis priejjimas atliekant PKI, tačiau tai yra susiję su didele kraujavimo ir mirtingumo rizika (2). Transradialinès koronarinès intervencijos sèkmę lemia palankus anatominių struktūrų išsidèstymas apie radialinę arteriją šalia jos nėra stambių venų ir nervų, dèl to atliekant PKI minimalizuojamas šių struktūrų pažeidimas. Dèl radialinès arterijos paviršinès eigos hemostazè lengvai gali būti igyvendinta lokalios kompresinès taktikos. Trombozine ar trauminè arterijos okliuzija nekelia grèsmès rankos gyvybinėms funkcijoms, jei yra adekvatus kraujo pritekejjimas iš ulnarinès arterijos kolateralių (7). PKI ženkliai sumažina mirtingumo, reinfarkto ir insulto tikimybe palyginus su fibrinoliziu gydymu ir tapo priimtiniausia reperfuzijos taktika pacientams esant ST pakilimo miokardo infarktui (13).

Šiais laikais intervenciniams kardiologams yra aktuali problema, jog kraujavimas po PKI yra dažniausia ne kar- 
dialinè komplikacija, kuri yra susijusi su dideliais sergamumo, mirtingumo rodikliais $(1,3,4,5,12,16)$ ir faktoriu itaka kraujavimams nèra pakankamai ištirta nacionaliniu lygmeniu.

Darbo tikslas - išanalizuoti 2010 - $2012 \mathrm{~m}$. laikotarpio Vilniaus universiteto ligoninès Santariškių klinikų Kardiologinès reanimacijos ir intensyvios terapijos skyriuje (VUL SK KRITS) dèl ūminio miokardo infarkto (MI) gydytų pacientų kraujavimų dažnį pagal amžių, lytị, lokalizaciją, šalutines ligas, skirtų vaistų derinius, mirtingumą, kraujavusių pacientų mirčiu pasiskirstymą pagal lytị ir išnagrinèti šios tematikos mokslinès literatūros duomenis.

\section{Tyrimo medžiaga ir metodai}

Tiriamųjų populiacija ir statistinè analizè. Atlikta retrospektyvinè pacientų, gydytų $2010 \mathrm{~m}$. - $2012 \mathrm{~m}$. VUL SK Kardiologinès reanimacijos ir intensyvios terapijos skyriuje dèl ūminio miokardo infarkto medicininių ịrašų duomenų analizè. I tyrimą ịtraukti 223 pacientai (moterų 116; vyrų 107) (1 pav.). Šių pacientų amžiaus vidurkis $75 \pm 1,7 \mathrm{~m}$. Kraujavimas po perkutaninès koronarinès intervencijos konstatuotas 73 pacientams, sirgusiems ūminiu miokardo infarktu (2 pav.). Nagrinèti kraujavusių pacientų duomenys: lytis, amžius, kraujavimo lokalizaci-

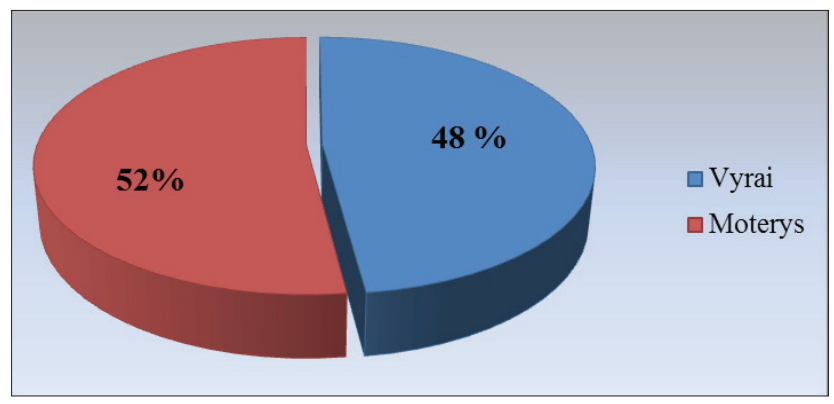

1 pav. Ūminiu MI sirgusių pacientų pasiskirstymas pagal lytị. VUL SK KRITS 2010 - $2012 \mathrm{~m}$. Per ši laikotarpi intensyvios terapijos skyriuje dèl ūminio MI moteru buvo 1,08 karto daugiau nei vyrų.

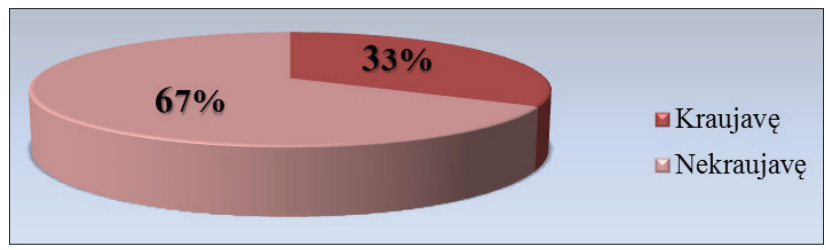

2 pav. Ūminiu MI sirgusių pacientų pasiskirstymas pagal kraujavimus po PKI procedūros. VUL SK KRITS 2010 - $2012 \mathrm{~m}$. Per ši laikotarpi po PKI kraujavusių buvo 2,03 karto mažiau nei nekraujavusių. ja, šalutinès ligos, paskirtų vaistų deriniai, mirtingumas. Duomenys statistiškai apdoroti SPSS 21 for Windows versija ir Microsoft Excel 2010. Lyginant gautus duomenų parametrus pasirinktose tiriamujjų grupèse, analičių skirtumai vadinti statistiškai reikšmingais, kai $\mathrm{p}<0,05$.

\section{Rezultatai}

Išanalizavus VUL SK KRITS medicininių įrašų 2010 - $2012 \mathrm{~m}$. duomenis nustatytas kraujavimų pasiskirstymas pagal lyti $(\mathrm{p}=0,034)(3$ pav. $)$.

Kraujavusiuju hemoglobino koncentracija buvo mažesnè nei $90 \mathrm{~g} / \mathrm{l}(\mathrm{p}=0,001)$. Amžiaus grupèse daugiausia kraujavimų turejjo pacientai $>60 \mathrm{~m} .(87 \%, \mathrm{n}=63)$, lyginant su kitų amžiaus grupių pacientų kraujavimais $-40-60 \mathrm{~m}$. $12 \%(\mathrm{n}=9),<40$ m. 1\% $(\mathrm{n}=1)(\mathrm{p}=0,001)$. Diagramoje vaizduojamas kraujavimų pasiskirstymas pagal lokalizaciją (4 pav.)

Nustatyta, jog kraujavę iš virškinimo trakto $40 \%$ pacientų sirgo opalige $(n=14)$ ir $11 \%(n=4)$ sirgo onkologine

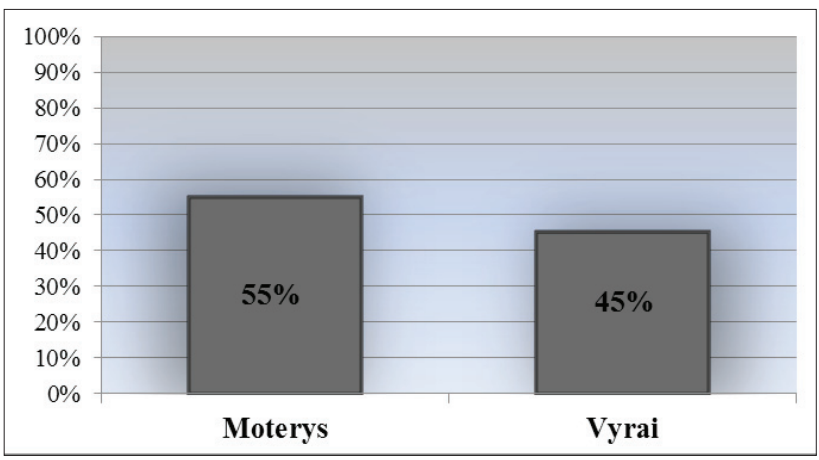

3 pav. Ūminiu MI sirgusių pacientų kraujavimų pasiskirstymas pagal lytị. VUL SK KRITS 2010 - 2012 m. Per 3 metų laikotarpi moterų kraujavo 1,2 karto daugiau nei vyrų $(\mathrm{p}=0.034)$.

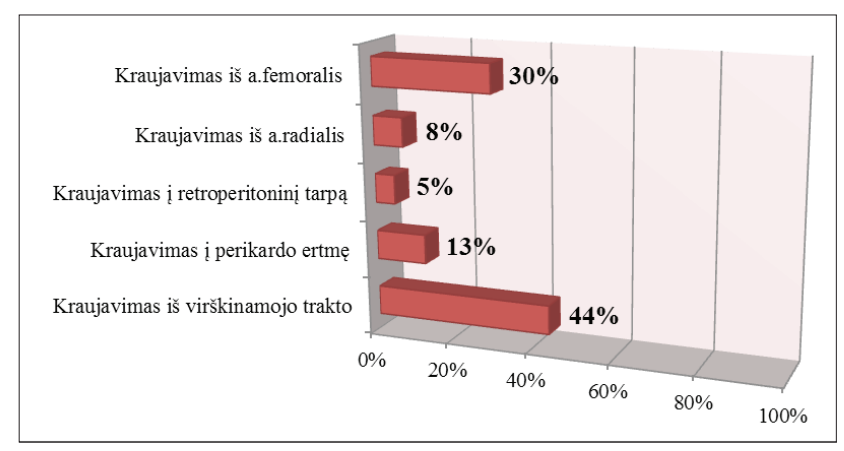

4 pav. Ūminiu MI sirgusių pacientų kraujavimų pasiskirstymas pagal lokalizaciją. VUL SK KRITS 2010 - 2012 m. Gautas didžiausias kraujavimų dažnis iš virškinimo trakto $(44 \%, \mathrm{n}=35)$ ir a.femoralis $(30 \%, \mathrm{n}=24)(\mathrm{p}=0,008)$ 
liga. $81 \%$ kraujavusiụjų turèjo: inkstų funkcijos nepakankamumą $11 \%$, prieširdžių virpejjimą $26 \%$, opaligę $19 \%$, cukrinį diabetą $15 \%$, onkologinę ligą $10 \%(\mathrm{p}=0,025)$. Ištirta, kad daugiausia kraujavimų ívyko kartu skiriant hepariną, aspiriną ir klopidogreli - 34\% $(n=25)$, mažiausiai - kartu skiriant hepariną, aspiriną ir varfariną $-1 \%$, taikant trombolizę kartu su heparinu $-1 \%(p=0,003)$. Išanalizuotas kraujavusių pacientų pasiskirstymas pagal mirtingumą: $16 \%$ turejo letalią baigtị $(\mathrm{p}=0,0076)$, iš kurių moterys sudarè didesnę dali nei vyrai, atitinkamai $-58 \%, 42 \%$.

\section{Aptarimas}

Didysis kraujavimas po PKI išlieka svarbiausia komplikacija intervencineje kardiologijoje ir yra mirtingumą didinantis rizikos veiksnys pacientams po ūminio MI (16). Didysis kraujavimas apibūdinamas kaip: intrakranialinis, intraokuliarinis, retroperitoninis kraujavimas, procedūros prieigos vietoje esanti hemoragija, reikalaujanti intervencijos, kateterizacijos vietoje esanti $5 \mathrm{~cm}$ skersmens hematoma, hemoglobino koncentracijos sumažejimas $\geq 4 \mathrm{~g} / \mathrm{dl}$ be atviro kraujavimo šaltinio, hemoglobino koncentracijos sumažejimas $\geq 3 \mathrm{~g} / \mathrm{dl}$ su atviru kraujavimo šaltiniu, pakartotinè operacija dèl kraujavimo ar atlikta kraujo transfuzija. Publikacijose minimos kraujavimų klasifikacijos pagal TIMI (Thrombolysis In Myocardial Infarction) ir GUSTO (Global Strategies for Opening Occluded Coronary Arteries) skales - TIMI kraujavimų klasifikacijoje išskirtos 4 kategorijos: didysis, mažasis, minimalus kraujavimas ir nenustatytas kraujavimas, pagal GUSTO taip pat skiriamos 4 kategorijos: labai sunkus arba gyvybei pavojingas, vidutinio sunkumo, nestiprus kraujavimas ir nenustatytas kraujavimas (19).

TIMI kraujavimo klasifikacijoje išskiriama: a) didysis kraujavimas, kai yra intrakranialine hemoragija ar hemoglobino koncentracija sumažejja $\geq 5 \mathrm{~g} / \mathrm{dl}$, ar absoliutus hematokrito sumažejimas $\geq 15 \%$; b) mažasis kraujavimas - hemoglobino koncentracijos sumažejimas yra $\geq 3 \mathrm{~g} / \mathrm{dl}$ ar hematokrito sumažejimas $\geq 10 \%$; hemoglobino koncentracijos sumažèjimas yra $\geq 4 \mathrm{~g} / \mathrm{dl}$ ar hematokrito sumažèjimas $\geq 12 \%$; c) minimalus kraujavimas - bet koks kliniškai akivaizdus hemoragijos požymis, kuris yra susijęs su hemoglobino koncentracijos sumažèjimu $<3 \mathrm{~g} / \mathrm{dl}$ ar hematokrito sumažejimu $<9 \%$. Pagal GUSTO klasifikaciją kraujavimai skirstomi $i$ a) labai sunkų arba gyvybei pavojingą - bet kokia intrakranialinè hemoragija, kuri sukelia hemodinamikos sutrikimą ir reikalauja intervencinio gydymo; b) vidutinio sunkumo kraujavimą, kuris reikalauja kraujo transfuzijos, bet nelemia hemodinamikos sutrikimo; c) nestipru kraujavimą - neatitinka nei labai sunkaus, nei vidutinio sunkumo kraujavimo kriterijų $(19,20)$.
Užsienyje publikuotuose tyrimuose minima, jog PKI klinikineje praktikoje nors ir retai atliekama per radialinę arteriją, tačiau tai yra susiję su tokia pačia procedūros sèkme kaip ir atliekant PKI per šlaunies arteriją ir mažesne kraujavimo ir kraujagysliu komplikacijų tikimybe. Todèl plačiau taikant PKI per radialinę arteriją galima padidinti PKI saugumą ir sumažinti lovadienių skaičių $(2,17)$.

Tarp pacientų, kuriems atliekama PKI, yra tam tikri pogrupiai, kuriems reikia skirti atitinkamą medicininę priežiūrą. Ekskliuduojamos tokios rizikos grupès kaip senyvo amžiaus žmonès, pacientai, sergantys cukriniu diabetu ir inkstų funkcijos nepakankamumu, turi didesnę kraujavimų riziką ir blogesnes išgyvenamumo prognozes (8). Minima svarbi rizikos grupe kaip moteriškos lyties atstovès, kurios po PKI procedūros turi kur kas didesnę kraujavimų riziką nei vyrai (3). Moters lytis yra rizikos faktorius pats savaime, jis lemia didesnį mirtingumą nei vyrų hospitalizacijos laikotarpiu po PKI procedūros, ir tik po 75 metų amžiaus stebimas reikšmingas mirtingumo skirtumas tarp skirtingų lyčių atstovų (9). Paminètina, jog kelių antitrombozinių vaistų vartojimas padidina kraujavimo riziką pacientams su ūminiu koronariniu sindromu, kuriems atliekama PKI procedūra (10). Didelès aspirino dozès (nuo 300 iki 325 mg per dieną) pacientams su ST segmento pakilimo MI, kuriems atliekama PKI, yra prognostinis faktorius didesniam kraujavimų dažniui (11). Mokslinèse publikacijose taip pat rašoma, kad didejjanti cistatino $\mathrm{C}(>2.04 \mathrm{mg} / \mathrm{L})$ ir endotelio ląstelių selektyvios adhezijos molekulès $(>34.3$ $\mathrm{ng} / \mathrm{mL}$ ) koncentracija yra susijusi su didesne kraujavimo rizika (12).

Svarbu paminèti, jog gastrointesticinis kraujavimas, kuris turi įtakos didesniam pacientu mirtingumui, yra susijęs su nefataliniu miokardo infarktu ir pailgejjusiais lovadieniais, todèl gydytojai turètų žinoti gatsrointesticinio kraujavimo didelès rizikos grupes, i kurias yra įtraukti senyvo amžiaus žmonès, rūkantieji ir pacientai, sergantys anemija $(14,15)$. Nustatytas mažesnis pacientų mirtingumas, kuriems reiškèsi viršutinès virškinimo trakto dalies kraujavimas, tai gali būti siejama su geresnemis diagnostikos technikomis ir dažniau naudojamu endoskopiniu gydymu šioje pacientų populiacijoje (15).

Užsienio moksliniuose tyrimuose lyginama fibrinolizė su PKI ir gautuose rezultatuose teigiama, kad prehospitaliné fibrinolizè su laiku atlikta koronarine angiografija lèmè veiksmingą reperfuziją pacientams esant ankstyvam miokardo infarktui su ST pakilimu, kai pirminès PKI procedūros nebuvo įmanoma padaryti per pirmą valandą po pirmojo kontakto su gydytoju. Nepaisant veiksmingumo, fibrinolizè turi neigiamų pasekmių - siejama su padidejusia intrakranialinio kraujavimo rizika (6). 


\section{Išvados}

Kardiologinès reanimacijos ir intensyvios terapijos skyriuje daugiausia kraujavimų buvo $>60 \mathrm{~m}$. amžiaus tiriamujų grupejje, turintiems šalutines ligas, moteriškos lyties atstovèms, virškinimo trakte ir iš a.femoralis, skiriant kartu hepariną, aspiriną ir klopidogreli. Nustatyta, kad kraujavusių pacientų mirties atvejai dažnesni moterims. Esant šioms išvardintoms tiriamųjų rizikos grupèms, turetų būti koreguojamas gydymas antikoaguliaciniais vaistais, dèl mažesnio komplikacijų dažnio rekomenduojamas kateterizavimas per a.radialis / brachialis.

\section{Literatūra}

1. Flores-Rios X, Couto-Mallon D, Rodriguez-Garrido J, GarciaGuimaraes M. et al. Comparisom of the permormance of the CRUSADE, ACUITY-HORIZONS, and ACTION bleeding risk scores in STEMI undergoing primary PCI: insights from a cohort of 1391 patients. European Heart Journal: Acute Cardiovascular Care. 2012; 2 (I): 19-26.

2. Rao VS, Wang TY, Brindis R, Rumsfeld JS, Peterson ED. et al. Trends in the prevalence and outcomes of radial and femoral approaches to percutaneous coronary intervention. JACC: Cardiovascular Interventions. 2008 August; 379-86.

3. Daugherty SL, Thompson LE, Rao SV, Subherwal S, Messenger JC. et al. Patterns of Use and Comparative Effectiveness of Bleeding Avoidance Strategies in Men and Women Following Percutaneous Coronary Interventions: An Observational Study from the National Cardiovascular Data Registry Journal of the American College of Cardiology. 2013 February 19; (13).

4. Chhatrivalla AK, Admin AP, Kennedy KF, House JA, Cohen DJ. et al. Association between bleeding events and in-hospital mortality after percutaneous coronary intervation. JAMA. 2013; (10): 1022 - 1029.

5. Verheugt FWA, Steinhubl SR, Hamon M, Darius H, Steg PG. et al. Incidence, prognostic impact, and influence of ane tithrombotic therapy on access and nonaccess site bleeding in percutaneous coronary intervention. JACC: Cardiovascular Interventions. 2011; 191-7.

6. Armstrong PW, Gershlick AH, Goldstein P, Wilcox R, Danays T. et al. Fibrinolysis or Primary PCI in ST-Segment Elevation Myocardial Infarction. The new england journal of medicine. 2013.

7. Kiemeneij F, Laarman GJ, Odekerken D, Slagboom T. et al. A Randomized comparison approaches: the access study. J Am Coll Cardiol. 1997;(29):1269-75.

8. De Luca L, Tomai F, Verdoia M, De Luca G. Evaluation and management of special subgroups after primary percutaneous coronary intervention. Am Heart J. 2010; (160):S22-S27.

9. Mrdovic I, Savic L, Asanin M, Cvetinovic N, Brdar N. et al. SexRelated Analysis of Short- and Long-term Clinical Outcomes and Bleeding Among Patients Treated With Primary Percuta- neous Coronary Intervention: An Evaluation of the RISK-PCI Data. 2013; 1-7.

10. Mehran R, Pocock S, Nikolsky E, Dangas GD, Clayton T. et al. Impact of Bleeding on Mortality After Percutaneous Coronary Intervention. JACC: Cardiovascular Interventions. 2011; 654-64.

11. Yu J, Mehran R, Dangas GD, Claessen BE. et al. Safety and Efficacy of High- Versus Low-Dose Aspirin After Primary Percutaneous Coronary Intervention in ST-Segment Elevation Myocardial Infarction. JACC: Cardiovascular Interventions. 2012. 1231-8.

12. Kikkert WJ, Claessen BE, Stone GW, Mehran R, Witzenbichler B. et al. Relationship between biomarkers and subsequent bleeding risk in ST-segment elevation myocardial infarction patients treated with paclitaxel-eluting stents: a HORIZONSAMI substudy. 2013; (35): 200-208.

13. Tobbia P, Brodie1 BR, Witzenbichler B, Metzger C. et al. Advere se event rates following primary PCI for STEMI at US and non-US hospitals: three-year analysis from the HORIZONSAMI trial. Eurointervention. 2013; (8):1134-1142.

14. Nikolsky E, Stone GW, Kirtane AJ, Dangas GD, Lansky AJ. et al. Gastrointestinal Bleeding in Patients With Acute Coronary Syndromes: Incidence, Predictors, and Clinical Implications: Analysis From the ACUITY (Acute Catheterization and Urgent Intervention Triage Strategy) Trial. Journal of the American College of Cardiology. 2009; (54): 1293-302.

15. Wilcox CM, Cryer BL, Henk HJ, Zarotsky V, Zlateva G. Mortality associated with gastrointestinal bleeding events: Comparing short-term clinical outcomes of patients hospitalized for upper GI bleeding and acute myocardial infarction in a US managed care setting. Clinical and Experimental Gastroenterology. 2009; (2): 21-30.

16. Won Suh J, Mehran R, Claessen BE, Xu K., Baber U. et al. Impact of In-Hospital Major Bleeding on Late Clinical Outcomes After Primary Percutaneous Coronary Intervention in Acute Myocardial Infarction: The HORIZONS-AMI (Harmonizing Outcomes With Revascularization and Stents in Acute Myocardial Infarction) Trial. Journal of the American College of Cardiology. 2011; (58): 1750-6.

17. Jolly SS, Amlani S, Hamon M, Yusuf S, Mehta SR. et al. Radial versus femoral access for coronary angiography or intervention and the impact on major bleeding and ischemic events: A systematic review and meta-analysis of randomized trials. American Heart Journal. 2009; (157): 132-140.

18. Mann T, Cubeddu G, Bowen J, Schneider JE. et al. Stenting in acute coronary syndromes: a comparison of radial versus femoral access sites FREE. J Am Coll Cardiol. 1998; (32): 572-576.

19. Rao SV, O'Grady K, Pieper KS, Granger CB, LK. Newby et al. Comparison of the Clinical Impact of Bleeding Measured by Two Different Classifications Among Patients With Acute Coronary Syndromes. Journal of the American College of Cardiology. 2006; (47): 809-816. 
20. Mehran R, Pocock SJ, Stone GW, Clayton TC. et al. Associations of major bleeding and myocardial infarction with the incidence and timing of mortality in patients presenting with non-ST-elevation acute coronary syndromes: a risk model from the ACUITY trial. European Heart Journal. 2009; (30): 1457-1466.

WHAT FACTORS INFLUENCE MAJOR BLEEDINGS IN PATIENTS SICK WITH ACUTE MYOCARDIAL INFARCTION IN CARDIOLOGIC INTENSIVE CARE?

P. Šerpytis, A. Beržiūnaitė, V. Matelytè, Ž. Lileikienè,

A. Andruškienè

Key words: bleeding, myocardial infarction, percutaneous coronary intervention, mortality rate.

Summary

Aim of study: to investigate the frequency of bleeding events by age, sex, location, accompanying diseases, drug combinations, and distribution of deaths among bleeding patients by gender for patients with acute myocardial infarct hospitalized to Vilnius university hospital Santariškių klinikos Cardiologic intensive care unit in 2010 - 2012 and having blood transfusions.

Materials and methods: a retrospective analysis of medical records of 223 patients treated for acute myocardial infarction. $33 \%$ patients had bleeding events, the mean age of them $75 \pm 1.7$ years. It was analyzed the following data of bled patients: gender, age, location of bleeding, accompanying diseases, prescribed medication combinations and mortality rate.
Results: the distribution of bleeding events by gender: $55 \%$ of women and $45 \%$ of men $(p=0.034) .63 \%$ of bled patients had hemoglobin below $90 \mathrm{~g} / \mathrm{l}(\mathrm{p}=0.001)$. Most common bleeding was in the group of age more than 60 years old $(87 \%)(p=0.001)$. A statistically reliable highest frequency of bleeding according location was gastrointestinal tract $(44 \%)$ and femoral artery $(30 \%)$ $(\mathrm{p}=0.008)$. It was found that $81 \%$ of bled patients had accompanying diseases: $11 \%$ renal insufficiency, 26\% atrial fibrillation, $19 \%$ ulcer, $15 \%$ diabetes mellitus, $10 \%$ oncological diseases $(\mathrm{p}=$ $0.025)$. It was ascertained that bleeds occurred mostly with combination of heparin, aspirin and clopidogrel prescribed $-34 \%(\mathrm{p}=$ $0,003)$. The distribution of bled patients by mortality: $16 \%$ had a lethal outcome $(p=0.0076)$ of which women composed a higher proportion than men, respectively $-58 \%$ and $42 \%$.

Conclusions: the bleeding in the intensive care unit mainly occurred in $>60$ years age group of patients, patients with accompanying diseases, female representatives, as regards the location, in the gastrointestinal tract and femoral artery, prescribing in combination of heparin, aspirin and clopidogrel. Death of bled patients frequently occurred to women. In case of listed risk groups the treatment with anticoagulants should be adjusted. In order to reduce the rate of complications the catheterisation through a.radialis or brachialis is recommended.

Correspondence to: pranas.serpytis@santa.1t

Gauta 2013-05-27 